\title{
Numerical Analysis of Natural Convection Heat Transfer Inside an Inverted T-Shaped Cavity Filled with Nanofluid
}

\author{
Gopal Sen*, Mohammad Ilias Inam
}

Department of Mechanical Engineering, Khulna University of Engineering \& Technology, Khulna-9203, Bangladesh

Received: August 19, 2021, Revised: November 12, 2021, Accepted: November 13, 2021, Available Online: November 29, 2021

\begin{abstract}
This assessment is centered on the characteristics of natural convection heat transfer of Aluminium Oxide-Air nanofluid inside an inverted T-shaped enclosure with differentially heated sidewalls. The left edges of the enclosed cavity have been treated as a heated wall and are kept at a constant temperature. The right edges are also maintained at a constant temperature but lower than the heated wall. The top and bottom faces of the cavity have been considered adiabatic. The evaluation has been numerically investigated using ANSYS fluent. The effect of different significant parameters like volume fraction of nanoparticles, the shape of the enclosure, and Rayleigh number on the heat transfer characteristics inside an inverted $\mathrm{T}$ shape enclosure have been investigated. In this numerical analysis, a series of DNS simulations have been conducted for different Rayleigh numbers in the range of $10^{3}$ to $10^{6}$, the volume fraction of particles in the range $0 \leq \varphi \leq 0.1$, and for the different aspect ratios for the inverted $T$ shape have been conducted. The outcomes of this CFD analysis indicate a remarkable rise in the average heat transfer coefficient with the rising volume fraction of $\mathrm{Al}_{2} \mathrm{O}_{3}$ particles in the air. An increase of the average Nusselt number was also observed with the increase of Rayleigh number, but it drops slightly at a higher volume fraction of nanoparticles due to an increase in conductive heat transfer. For Rayleigh numbers $\geq 10^{4}$, both the average Nusselt number and average heat transfer coefficient decrease up to a certain shape of the cavity aspect ratio. After that cavity aspect ratio, both the parameters value increase. But in the case of Rayleigh number $=10^{3}$, both of the values decrease with the increase in the cavity aspect ratio.
\end{abstract}

Keywords: Natural Convection, Inverted T-shape, $\mathrm{Al}_{2} \mathrm{O}_{3}$ Nanoparticle, CFD, Nusselt Number.

This work is licensed under a Creative Commons Attribution-Non Commercial 4.0 International License.

\section{Introduction}

The natural convective heat transfer process has been practiced by engineers as well as scientists all over the world within the ancient time having a noteworthy augmentation in the cooling mechanism of enormous engineering systems because of its being simple, cheap at cost, comparatively low commotion, little in size, and for having unwavering quality. A survey has been demonstrated that investigating the natural convection characteristics in closed cavities having different shapes and sizes has originated significant zeal among analysts in the preceding decades. In the greater part of such investigations, it has been invented that using only base fluids as a heat transfer medium in the enclosure possesses lower thermal conductivity, which puts a limit on the increment of heat transfer in the walledin area. Conventional fluids, as like water, ethylene glycol, and also different engine oils are typically utilized as base heat transfer fluids. Nanofluids, which are created from dispersed nano-sized particles in general conventional fluids are profoundly effective liquids in the case of heat transfer that is used in various industrial and mechanical applications. Choi [1] built up the possibility of a nanofluid and it made a tremendous transformation in the case of heat transfer in fluids. The nanoparticle size utilized in nanofluids is from $1 \mathrm{~nm}$ to $100 \mathrm{~nm}$. Such nanoparticles can be made of variant metal materials, for instance, copper, silver, or from metal oxides, for example, aluminum oxide, copper and diamond oxide, and carbon nanotubes [2]. It is normal that using nanoparticles in nanofluids gradually enhance the heat conductivity and in this way generously upgrade various heat transfer characteristics of those nanofluids. Eastman et al. [3], Xie et al. [4], and Jana et al. [5] demonstrated that higher heat transfer ability can be accomplished in thermal systems using nanofluids. Xuan and Li [6] tentatively concentrated on the heat conductivity of a nanofluid comprising $\mathrm{Cu}$ nanoparticles mixed with base fluid. Their information clarified that dispersed nanoparticles expanded the heat conductivity than using pure fluid only. Thermal conductivity of nanofluid increases in a gradual way with expanding the volume portion of nanoparticles. For instance, the heat conductivity of $\mathrm{Cu}$-water nanofluid rises from 1.24 to 1.78 then the base fluid when the volume fraction of $\mathrm{Cu}$ particles has been changed from 2.5 to $7.5 \%$. Comparable behavior was accounted for by Eastman et al. [7], who got a 60\% expansion in heat conductivity with a $5 \%$ volume fraction of $\mathrm{CuO}$ particles dispersed in water. Nnanna [8] tentatively analyzed the heat transfer conduct of a buoyancy-driven $\mathrm{Al}_{2} \mathrm{O}_{3}-$ water nanofluid in a 2-D rectangular enclosed cavity that has differentially heating vertical walls and adiabatic horizontal walls. He built up an experimental relation for Nusselt number having a close relationship with the volume fraction percentage of the nanoparticles as well as Rayleigh number and contended that the upgraded heat transfer value can be accomplished at a little volume portion of nanoparticles.

Mohamed Ali et al. [9] experimented on natural convection heat transfer that has been carried out inside vertical and circular enclosures and that are filled with Aluminium-water nanofluid having different concentrations such as $0.0 \%, 0.85 \%, 1.98$, and $2.95 \%$ by mass. The results of this experiment show that the Nusselt number found for alumina-water nanofluid is less than base fluid. C.J. Ho et al. [10] undertook an experiment on natural convection heat transfer of alumina-water nanofluid in some 
vertical square enclosures having different sizes. For the nanofluid containing a much lower particle fraction of 0.1 volume, the percentage of heat transfer increased by around $18 \%$ compared with that of water. It is apparent from the discussion that the heat conductivity of nanofluids is a summation component of conductivity of base fluid and the nanoparticle material, volume fraction percentage, the enclosure surface portion, and the shape of nanoparticles dispersed. There has not any hypothetical formula as of the present time accessible for determining the exact forecast of the heat conductivity of nanofluid. A few examinations of convective heat transfer using nanofluid have been accounted for in the discussion. Literature discussion shows that there is no comprehensive and analytical study on natural convection heat transfer of nanofluid inside an inverted T-shaped cavity including an air-based mixture of nanoparticles functionalized multi-walled Aluminium made cavity. There is no comprehensive and analytical study on natural convection heat transfer of nanofluid inside an inverted T-shaped cavity having an air-based mixture of nanoparticles functionalized multi-walled Aluminium made cavity. T shape cavities can be used in different heat transfer applications. Air is abundant in the environment and can be easily collected. Its collection is a very cheap process. But it is rarely used as a heat transfer base fluid because it is very low thermal conductive. As air is low heat-conductive, particle volume fraction up to $10 \%$ has been used here. Very few assessments can be found where such a huge amount of volume fraction has been used. Therefore, the purpose of the analytical study is for considering the natural convection of nanofluid inside of an inverted T-shaped cavity for various Rayleigh numbers, particle volume percentage, and geometric variables.

\section{Problem Statement}

The geometry of an inverted T-shaped cavity is shown in Fig. 1. The uppermost surface is denoted as $\mathrm{x}$ and the bottom surface is denoted as $\mathrm{L}$. The length of $\mathrm{L}$ is constant $0.1 \mathrm{~m}$. Then the analysis has been performed for different $\mathrm{x} / \mathrm{L}$ Ratios. That ratio is been expressed by $\chi$. It is to be noted that $\mathrm{x}=\mathrm{y}$ for all the enclosure shapes. Firstly, free convective heat transfer characteristics were determined using only air inside the cavity. Then the nanoparticles have been added gradually. The nanofluid is air-based which has $\mathrm{Al}_{2} \mathrm{O}_{3}$ as nanoparticles. In this study, $\mathrm{Al}_{2} \mathrm{O}_{3}$ nanoparticles with a $2 \mathrm{~nm}$ average diameter were mixed with air with different concentrations (1-10\% volume fraction). A series of Rayleigh numbers that vary from $10^{3}$ to $10^{6}$ was considered for the determination of the average heat transfer coefficient and the average Nusselt number. On this direct simulation process, it has been assumed that the flow was steady, incompressible, and 2D. Additionally, Boussinesq approximation has also been considered running these DNS simulations. Therefore, the purpose of the numerical study is to analyze natural convection heat transfer of nanofluid inside an inverted T-shaped cavity for various Rayleigh numbers, particle volume percentage, and geometric variables.

\subsection{Boundary Conditions}

The temperature of the heated wall is $310 \mathrm{~K}$ and it is constant. On the other side, the temperature of the cooled wall is $300 \mathrm{~K}$ as constant. The flow inside the enclosure has been assumed to be laminar. The upper and lower walls of the cavity are kept thermally insulated (denoted by $\mathrm{x}$ and L in Fig. 1). It is assumed that the base fluid of the mixture (i.e. air) and the nanosized particles are in a thermal equilibrium state as well as a no-slip condition has been assigned between them. The thermophysical properties of the nanofluid are thought to be consistent except for the variation of density and which is approximated by the Boussinesq model.

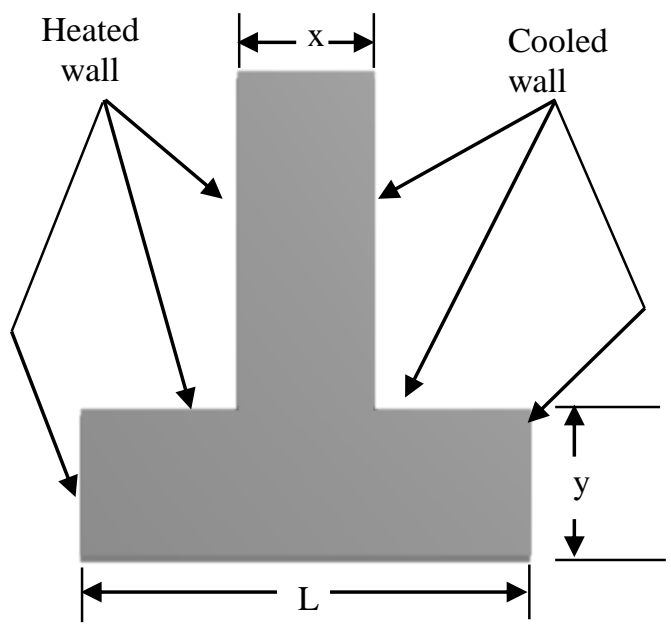

Fig. 1 Geometry as well as the boundary conditions of the inverted $\mathrm{T}$ shaped enclosure considered in this analysis

\section{Mathematical Modeling Details}

The continuity, momentum equation following Boussinesq approximation, and energy equations that have been used for the laminar and steady-state natural convection heat transfer inside the 2-D shaped enclosure can be written in dimensional forms as follows:

\section{Continuity Equation for mixture model:}

$\frac{\partial}{\partial t}\left(\rho_{m}\right)+\nabla \cdot\left(\rho_{m} \overrightarrow{v_{m}}\right)=0$

where $\overrightarrow{v_{m}}$ is the mass-averaged velocity and $\rho_{m}$ is the mixture density.

Momentum Equation for mixture model:

$$
\begin{aligned}
\frac{\partial}{\partial t}\left(\rho_{m} \overrightarrow{v_{m}}\right)+\nabla \cdot( & \left.\rho_{m} \overrightarrow{v_{m}} \overrightarrow{v_{m}}\right) \\
& =-\nabla p+\nabla \cdot\left[\mu_{m}\left(\nabla \cdot \overrightarrow{v_{m}}+\nabla \cdot \vec{v}_{m}^{T}\right)\right] \\
& +\rho_{m} \vec{g}+\vec{F} \\
& +\nabla \cdot\left(\sum_{k=1}^{n} \alpha_{k} \rho_{k} \vec{v}_{d r, k} \vec{v}_{d r, k}\right)
\end{aligned}
$$

where $n$ is the number of phases, $\vec{F}$ is a body force, and, $\mu_{m}$ is the viscosity of the mixture. $\vec{v}_{d r, k}$ is the drift velocity for secondary phase $k$.

Energy Equation for mixture model:

$$
\begin{aligned}
\frac{\partial}{\partial t} \sum_{k=1}^{n}\left(\alpha_{k} \rho_{k} E_{k}\right)+ & \nabla \cdot \sum_{k=1}^{n}\left(\alpha_{k} \vec{v}_{k}\left(\rho_{k} E_{k}+p\right)\right) \\
& =\nabla \cdot\left(k_{e f f} \nabla T\right)+S_{E}
\end{aligned}
$$

where $k_{e f f}$ is the effective conductivity $\left(\sum \alpha_{k}\left(k_{k}+k_{t}\right)\right)$, where $k_{t}$ is the turbulent thermal conductivity, defined according 
to the turbulence model being used. The first term on the righthand side of Eq. (6) represents energy transfer due to conduction. $S_{E}$ includes any other volumetric heat sources.

The effective density $\left(\rho_{n f}\right)$ and heat capacitance $\left(\rho c_{p}\right)_{n f}$ of the nanofluid are defined as [11]:

$$
\rho_{n f}=(1-\varphi) \rho_{f}+\rho_{s} \varphi
$$

$$
\left(\rho C_{p}\right)_{n f}=\left(\rho C_{p}\right)_{f}(1-\varphi)+\left(\rho C_{p}\right)_{s} \varphi
$$

where $\varphi$ is the solid volume fraction of nanoparticles in the mixture. Thermal diffusivity of the nanofluids is,

$$
\alpha_{n f}=\frac{k_{n f}}{\left(\rho c_{p}\right)_{n f}}
$$

and the thermal expansion coefficient of the nanofluids has been determined by the following equation,

$$
\beta_{n f}=\beta_{f}(1-\varphi)+\beta_{s} \varphi
$$

The equation of dynamic viscosity of the nanofluids given by Brinkman [12] is,

$$
\mu_{n f}=\frac{\mu_{f}}{(1-\varphi)^{2.5}}
$$

The effective thermal conductivity of nanofluid can be estimated by the Maxwell-Garnetts [13] model as following:

$$
\frac{k_{n f}}{k_{f}}=\frac{k_{s}+2 k_{f}-2 \varphi\left(k_{s}-k_{f}\right)}{k_{s}+2 k_{f}+2 \varphi\left(k_{s}-k_{f}\right)}
$$

The use of Eq. (9) is restricted for spherical sized nanoparticles only so that it cannot be accounted for other shapes of nanoparticles

Nusselt number and Rayleigh number are defined as follows:

$$
\begin{aligned}
& N u=\frac{h L}{k} \\
& R a=\frac{g \beta \Delta T x^{3}}{v \alpha}
\end{aligned}
$$

The thermophysical properties of base fluid air and Nanoparticles are given in Table 1 below:

Table 1 Thermophysical properties of air [14] and nano-particle [15].

\begin{tabular}{cccc}
\hline Property & Unit & Air & $\mathrm{Al}_{2} \mathrm{O}_{3}$ \\
\hline$\rho$ & $\left(\mathrm{kg} / \mathrm{m}^{3}\right)$ & 1 & 3880 \\
$C_{p}$ & $(\mathrm{~J} / \mathrm{kgK})$ & 1006.43 & 765 \\
$K$ & $(\mathrm{~W} / \mathrm{mK})$ & 0.0242 & 42.64 \\
$\beta$ & $(1 / \mathrm{K})$ & $3.2^{*} 10^{-9}$ & $8.46^{*} 10^{-6}$ \\
\hline
\end{tabular}

\section{Results and Discussion}

\subsection{Grid Independence Test}

The solutions found for using different mesh sizes in geometry have been studied for generating the independence of each solution. The grid independence test has been conducted for an enclosure having an $\mathrm{x} / \mathrm{L}$ ratio of 0.5 . The cavity has been assumed to be filled with air and $1 \% \mathrm{Al}_{2} \mathrm{O}_{3}$ mixture nanofluid. The test has been conducted for $\mathrm{Ra}=10^{5}$ as well as the average Nusselt number for each mesh has been recorded. The meshes have been produced using the all triangular method. It is clear from Fig. 2 that there is a slight change in the average Nusselt number for mesh elements 30000 .

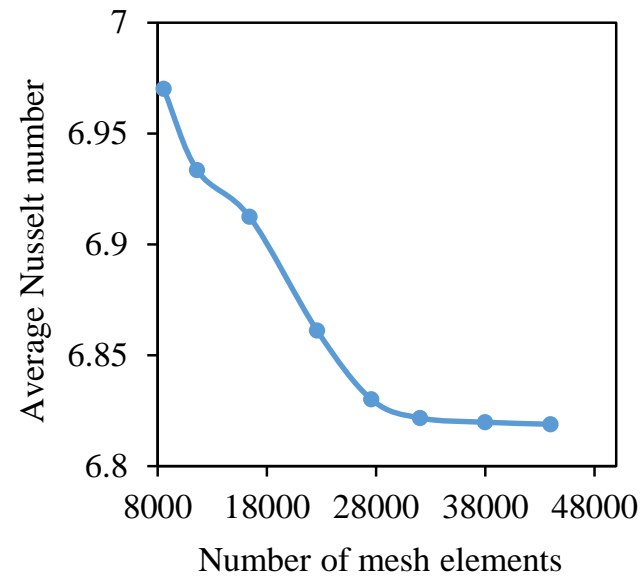

Fig. 2 Variation of average Nusselt number with the mesh elements

\subsection{Model Validation}

The model has been validated with solutions obtained from two previously published research articles that are shown in Table 2. Natural convection occurs air inside a square-shaped hollow cavity whose two sides are kept in different temperatures keeping the upper and lower surfaces at an adiabatic state might be a perfect case for model validation. The average Nusselt number has been calculated for the air-filled square cavity for four different Rayleigh numbers. Then the present work values have been compared with the values available within the literature. As a result, the values of average Nusselt numbers obtained from the present investigation are approximately the same within the values in the literature.

Table 2 Comparison of average Nusselt number for an air-filled square enclosure obtained by various studies with present study for various Rayleigh numbers.

\begin{tabular}{cccc}
\hline \multirow{2}{*}{ Ra } & \multicolumn{3}{c}{ Nu } \\
\cline { 2 - 4 } & Present work & N. C. Markatos [14] & Vahl Davis [15] \\
\hline $10^{3}$ & 1.117 & 1.108 & 1.118 \\
$10^{4}$ & 2.248 & 2.201 & 2.243 \\
$10^{5}$ & 4.55 & 4.430 & 4.519 \\
$10^{6}$ & 8.949 & 8.754 & 8.799 \\
\hline
\end{tabular}

4.3 Effects of Volume Fraction of Nanoparticle on Heat Transfer

The effects of nanoparticles on the stream functions and temperature distribution are shown in Fig. 3 to Fig. 14 for $\chi=0.3$, 0.6 , and 0.9 with nanoparticles for $\mathrm{Ra}=10^{5}$ and $10^{6}$. As it is seen the velocity components increase gradually with increasing particle volume fraction and it accelerates the energy transport within the nanofluid inside the enclosed cavity. 


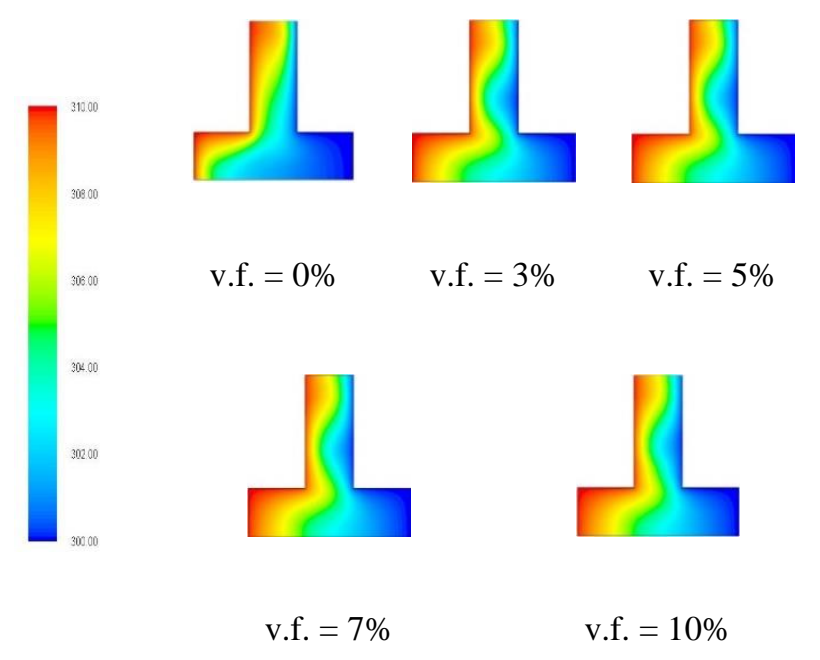

Fig. 3 Contours of Static temperature with and without Nanoparticle (For $\chi=0.3$ and $\mathrm{Ra}=10^{5}$ )

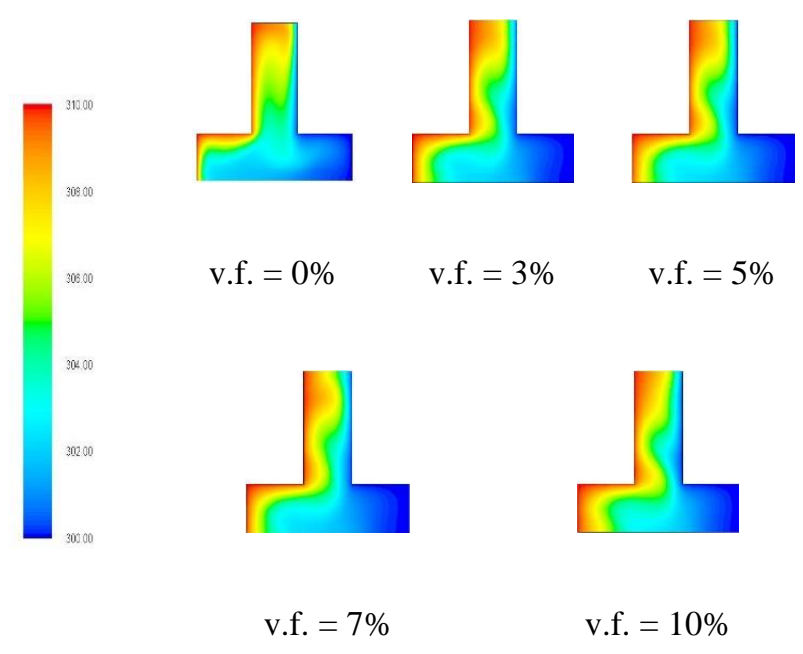

Fig. 4 Contours of Static temperature with and without Nanoparticle (For $\chi=0.3$ and $\operatorname{Ra}=10^{6}$ )

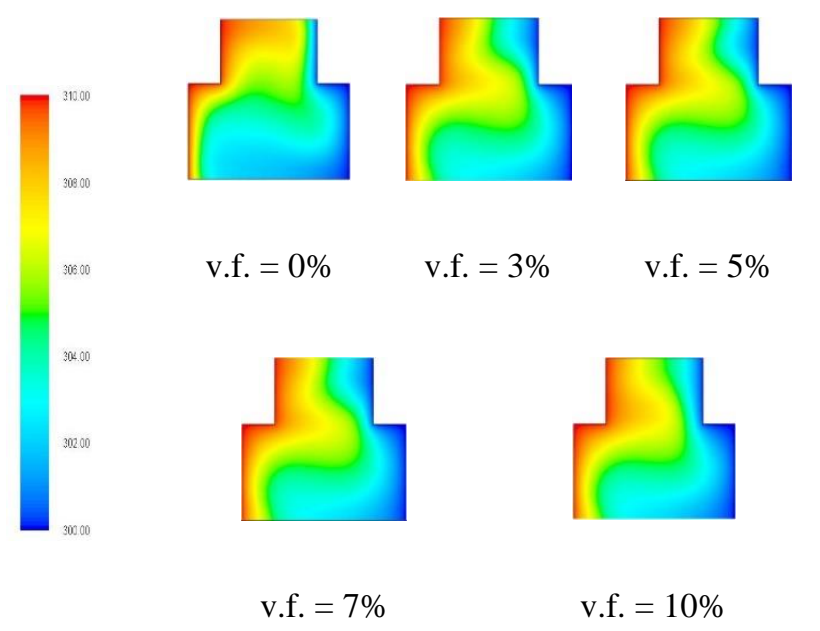

Fig. 5 Contours of Static temperature with and without Nanoparticle (For $\chi=0.6$ and $\mathrm{Ra}=10^{5}$ )
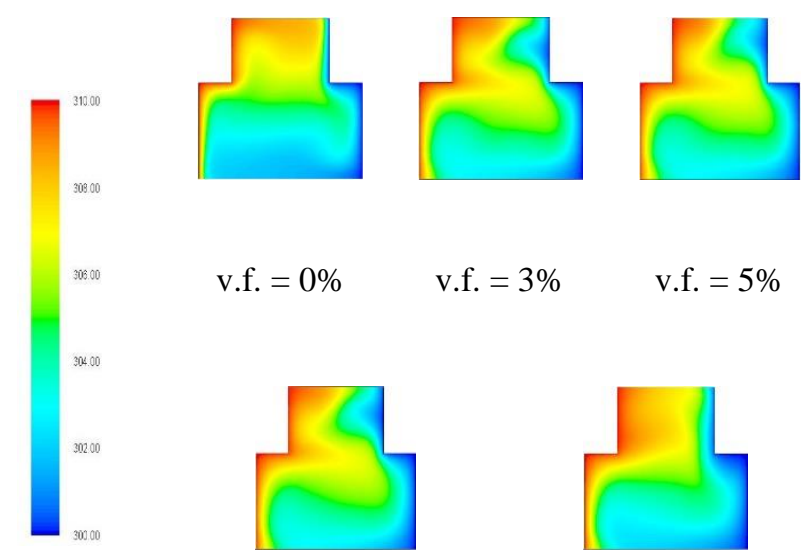

v.f. $=0 \%$

v.f. $=3 \%$

v.f. $=5 \%$
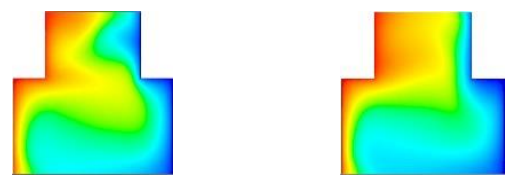

$$
\text { v.f. }=7 \%
$$$$
\text { v.f. }=10 \%
$$

Fig. 6 Contours of Static temperature with and without Nanoparticle (For $\chi=0.6$ and $\mathrm{Ra}=10^{6}$ )
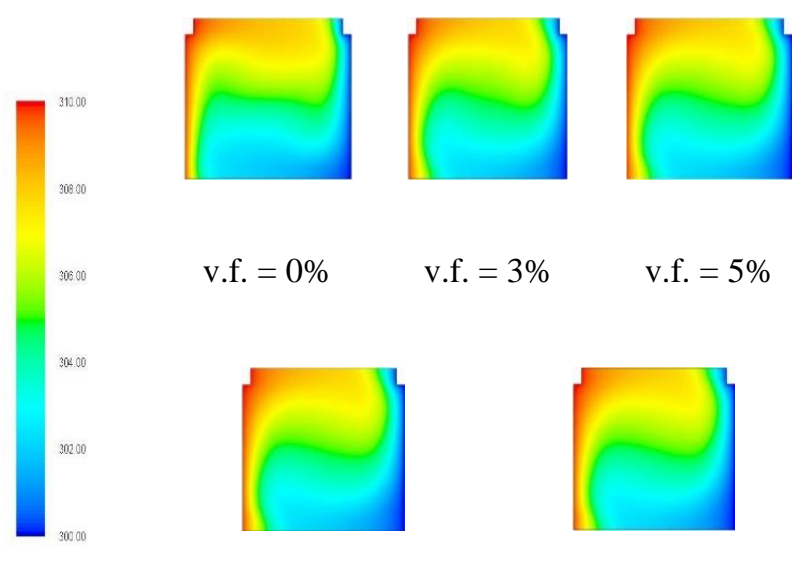

v.f. $=3 \%$

v.f. $=5 \%$

v.f. $=7 \%$

v.f. $=10 \%$

Fig. 7 Contours of Static temperature with and without Nanoparticle (For $\chi=0.9$ and $\mathrm{Ra}=10^{5}$ )
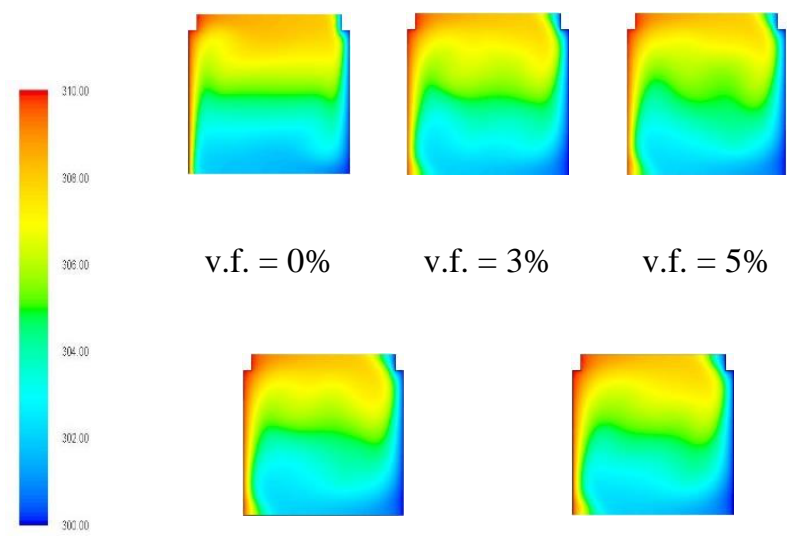

v.f. $=3 \%$

v.f. $=5 \%$

$$
\text { v.f. }=7 \%
$$

v.f. $=10 \%$

Fig. 8 Contours of Static temperature with and without Nanoparticle (For $\chi=0.9$ and $\mathrm{Ra}=10^{5}$ ) 
Thus, the real values of stream functions pointing that the strength of flow rises with the gradual rising of the volume fraction of nanofluid on the air and so the contour gets formed into a regular shape with the higher volume fraction. Maximum values of the stream functions are being increased with the increasing volume fraction and so, the streamline contours take a more regular shape in higher volume fractions. The change is due to equivalent thermal conductivity. For lesser volume fractions, the temperature change apportions within the fluid is also less than those of higher volume fractions. For high volume fraction change in temperature distribution is more prominent than a lower volume.

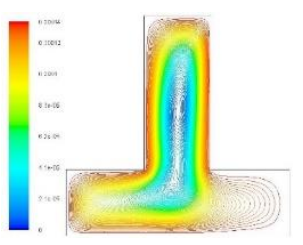

v.f. $=0 \%$

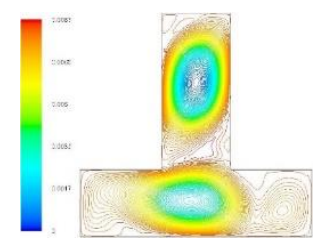

v.f. $=5 \%$

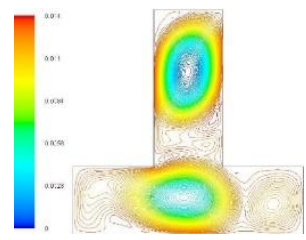

$$
\text { v.f. }=10 \%
$$

Fig. 9 Contours of Stream function with and without Nanoparticle (For $\chi=0.3$ and $\mathrm{Ra}=10^{5}$ )
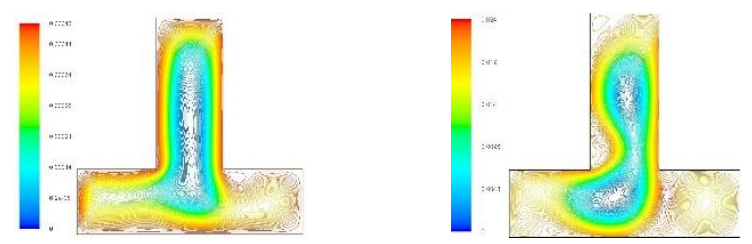

$$
\text { v.f. }=0 \%
$$

$$
\text { v.f. }=5 \%
$$

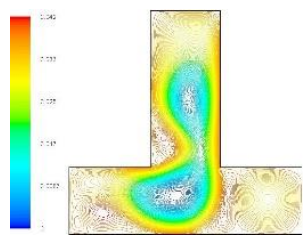

$$
\text { v.f. }=10 \%
$$

Fig. 10 Contours of Stream function with and without Nanoparticle (For $\chi=0.3$ and $\mathrm{Ra}=10^{6}$ )

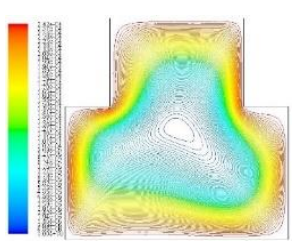

v.f. $=0 \%$

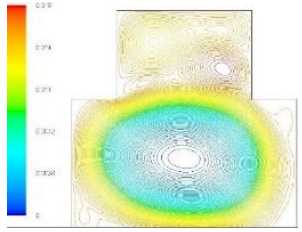

v.f. $=5 \%$

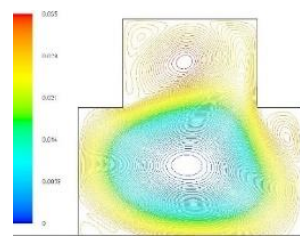

$$
\text { v.f. }=10 \%
$$

Fig. 11 Contours of Stream function with and without Nanoparticle (For $\chi=0.6$ and $\mathrm{Ra}=10^{5}$ )

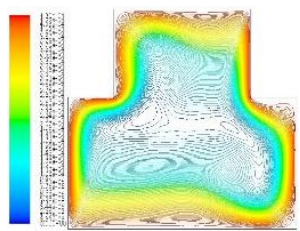

v.f. $=0 \%$

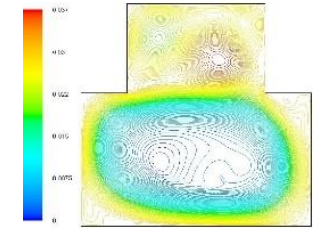

v.f. $=5 \%$

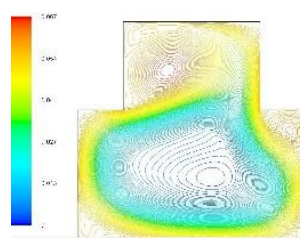

$$
\text { v.f. }=10 \%
$$

Fig. 12 Contours of Stream function with and without Nanoparticle (For $\chi=0.6$ and $\mathrm{Ra}=10^{6}$ )

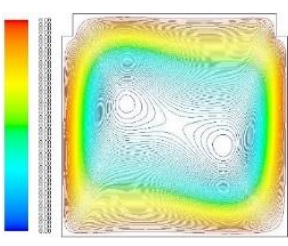

v.f. $=0 \%$

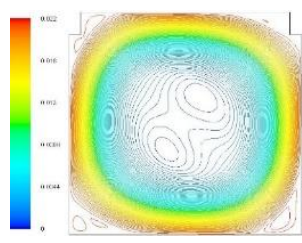

v.f. $=5 \%$

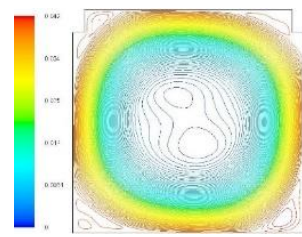

$$
\text { v.f. }=10 \%
$$

Fig. 13 Contours of Stream function with and without Nanoparticle (For $\chi=0.9$ and $\operatorname{Ra}=10^{5}$ ) 


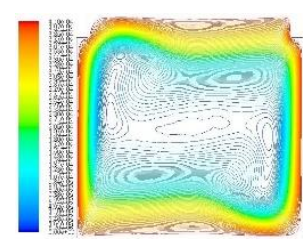

v.f. $=0 \%$

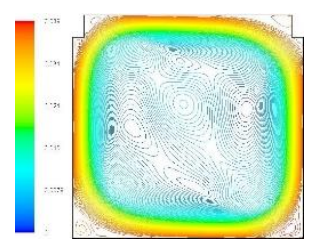

v.f. $=5 \%$

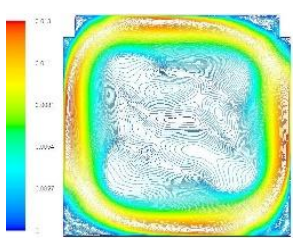

v.f. $=10 \%$

Fig. 14 Contours of Stream function with and without Nanoparticle (For $\chi=0.9$ and $\mathrm{Ra}=10^{6}$ )

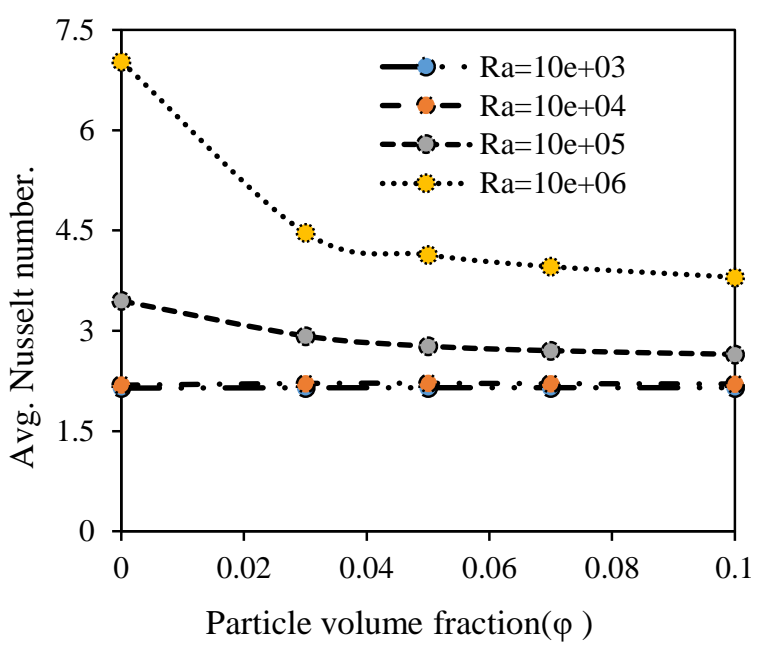

(a)

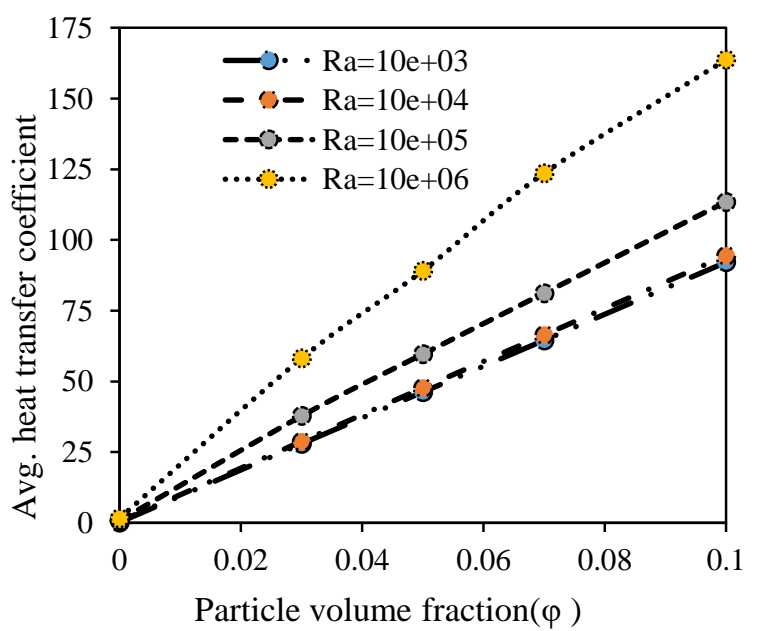

(b)

Fig. 15 Variation of average (a) Nusselt number and (b) Average convective heat transfer coefficient with volume fraction for different Rayleigh numbers (for $\chi=0.3$ )
A higher rate of thermal conductivity of nanofluid may be attained by having a higher rate of thermal diffusivity. The high thermal diffusivity results in a drop of temperature gradients and so increases the boundary thickness. Such an increase in the thermal boundary layer thickness reduces the Nusselt number.

With the rising Rayleigh number, the highest magnitude of the stream functions also rise. These phenomena occur because of the buoyancy effect. The consequences of the Rayleigh number on the average Nusselt number and average heat transfer coefficient can also be seen in the figures. Both of those parameter values gradually rise with the increment of Rayleigh number in all the shapes of enclosures.

A variation on temperature and stream function for different $\mathrm{x} / \mathrm{L}$ ratios of the cavity $(\chi)$ can also be seen on the contours above. With the increasing value of $\chi$, there is a significant difference in the contours. It has been seen by analyzing the contours that temperature distribution, as well as stream function, is prominently maximum when $\chi$ approximates unity.

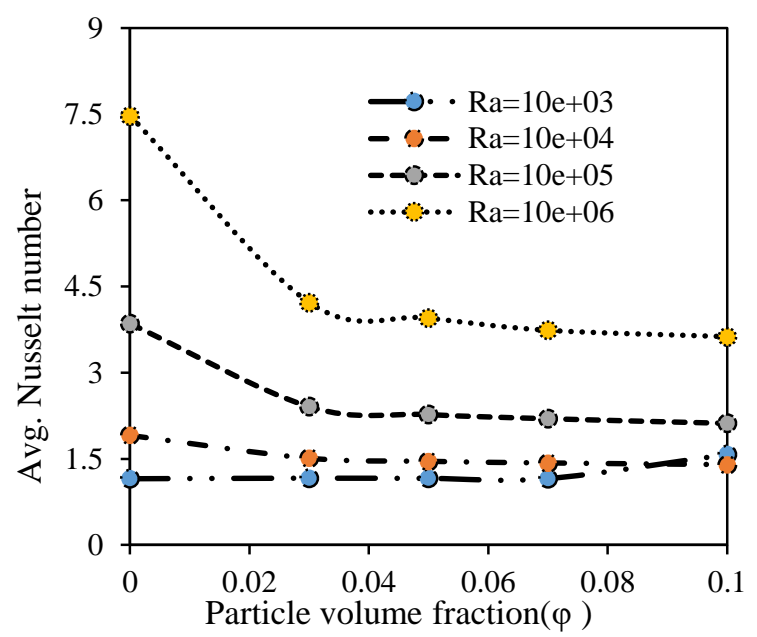

(a)

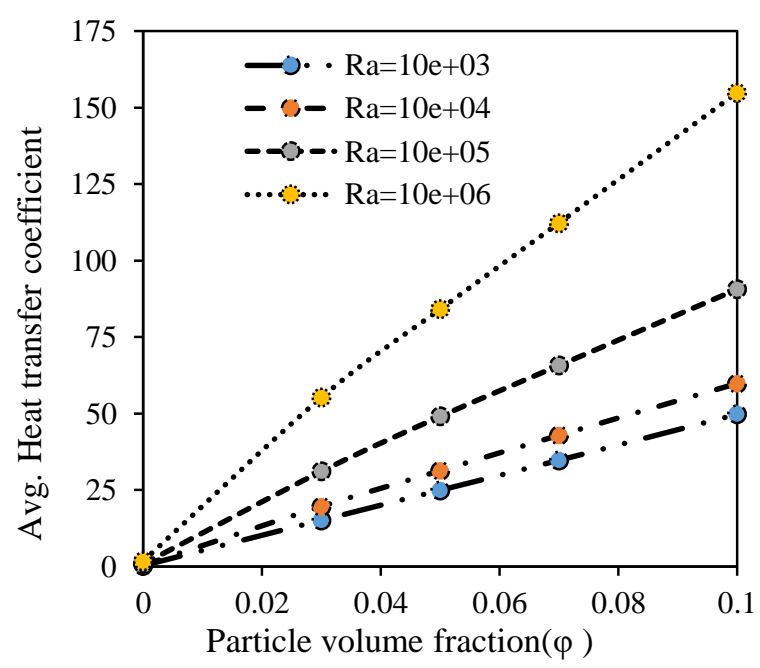

(b)

Fig. 16 Variation of average (a) Nusselt number and (b) convective heat transfer coefficient with volume fraction for different Rayleigh numbers (for $\chi=0.6$ ) 


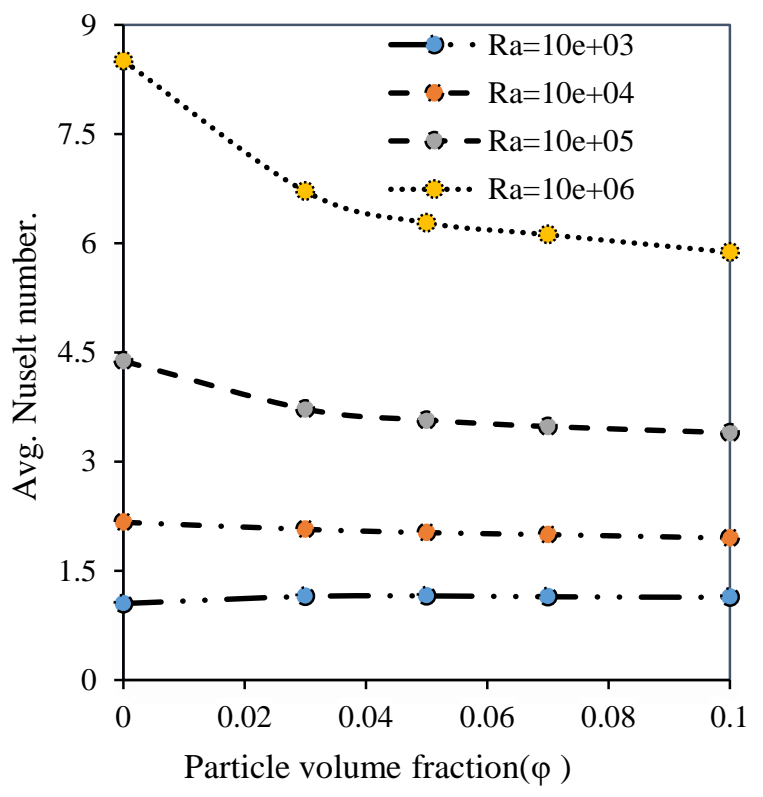

(a)

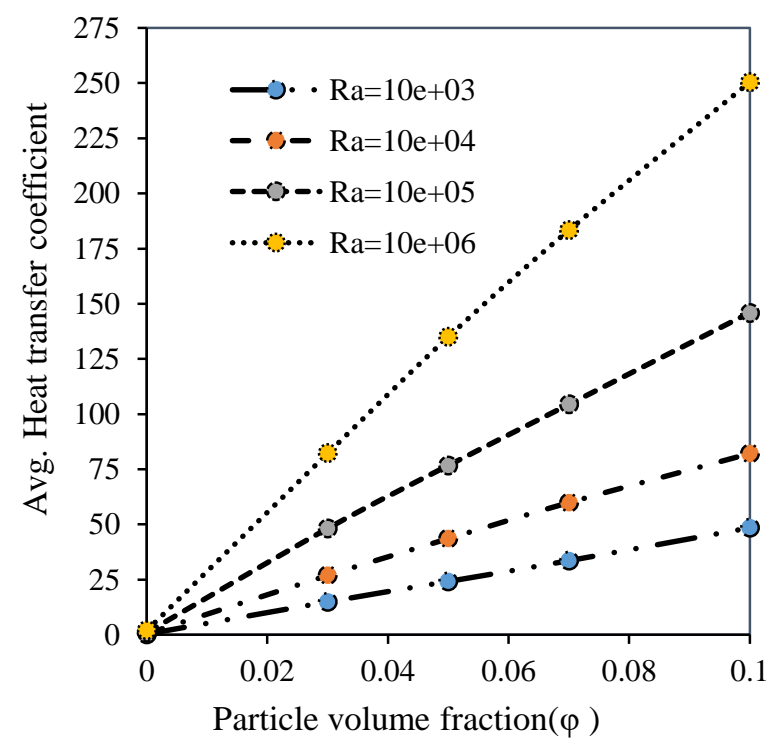

(b)

Fig. 17 Variation of average (a) Nusselt number and (b) convective heat transfer coefficient with volume fraction for different Rayleigh numbers (for $\chi=0.9$ )

Fig. 15-Fig. 17 show that the average heat transfer coefficient rises with the growing volume fraction and Nusselt number downfalls with the rising volume fraction. The reason for happening this is, besides the increasing convective heat transfer coefficient, thermal conductivity also rises so that increase in conductive heat transfer is more significant than convection. From Fig. 9(a), Fig. 10(a) and Fig. 11(a), an increase of average Nusselt number can be observed with the increase of Rayleigh number, but it drops slightly at a higher volume fraction of nanoparticles due to an increase in conductive heat transfer.

\subsection{Effect of Rayleigh Number on Heat Transfer}

Contours of static temperature and stream functions are exhibited in Fig. 18-23. With the increasing Rayleigh number, there occur noteworthy changes in the contours. For less value of
Rayleigh number, there is a slight change in the contour, but with the gradual rise of Rayleigh number, there is noteworthy variation in temperature distribution. In the case of stream function, with rising Rayleigh number highest magnitude of stream function also rises. These phenomena occur because of the buoyancy effect. The consequences of the Rayleigh number on the average Nusselt number and average heat transfer coefficient can also be seen in Fig. 15-17. Both of those parameter values gradually rise with the increment of Rayleigh number in all the shapes of enclosures.

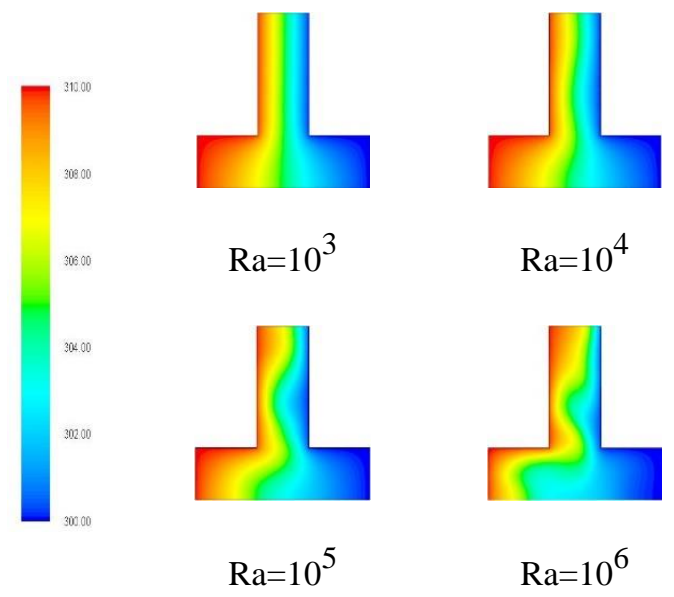

Fig. 18 Contours of Static temperature for different Rayleigh number (for $\varphi=0.1$ and $\chi=0.3$ )
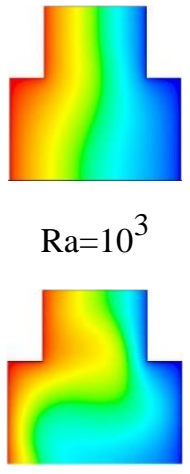

$\mathrm{Ra}=10^{5}$

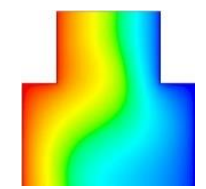

$\mathrm{Ra}=10^{4}$

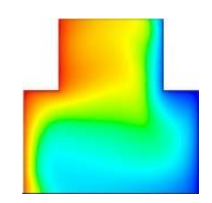

$\mathrm{Ra}=10^{6}$
Fig. 19 Contours of Static temperature for different Rayleigh number (for $\varphi=0.1$ and $\chi=0.6$ )
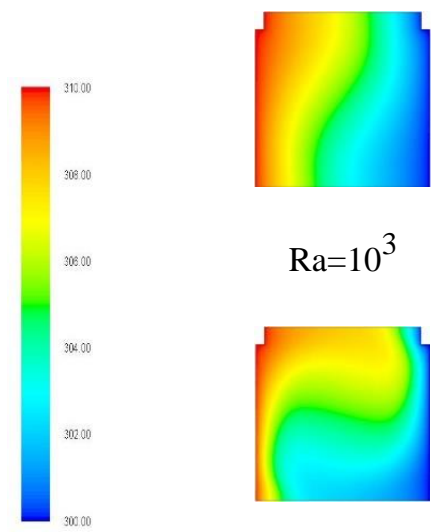

$$
\mathrm{Ra}=10^{3}
$$

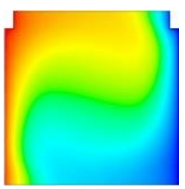

$$
\mathrm{Ra}=10^{5}
$$

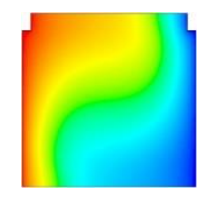

$\mathrm{Ra}=10^{4}$

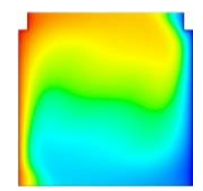

$\mathrm{Ra}=10^{6}$
Fig. 20 Contours of Static temperature for different Rayleigh number $($ for $\varphi=0.1$ and $\chi=0.9$ ) 


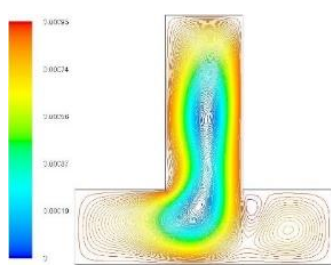

$\mathrm{Ra}=10^{3}$

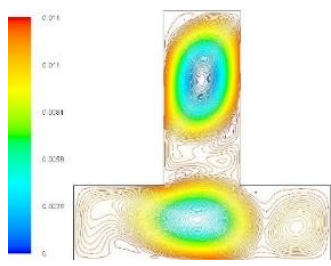

$\mathrm{Ra}=10^{5}$
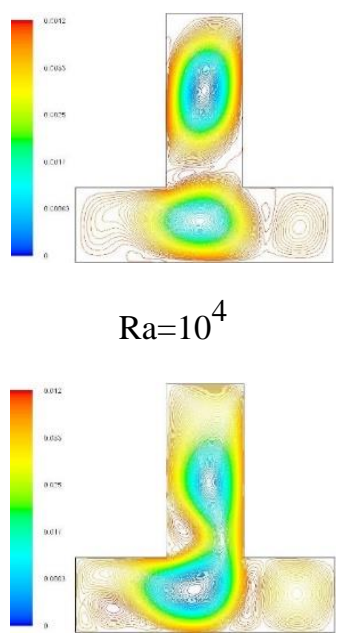

$\mathrm{Ra}=10^{6}$
Fig. 21 Contours of Streamlines for different Rayleigh number (for $\varphi=0.1$ and $\chi=0.3$ )

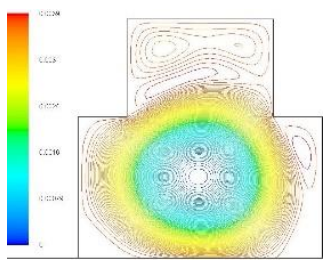

$\mathrm{Ra}=10^{3}$

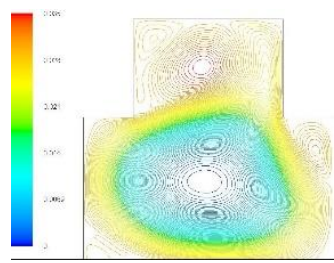

$\mathrm{Ra}=10^{5}$

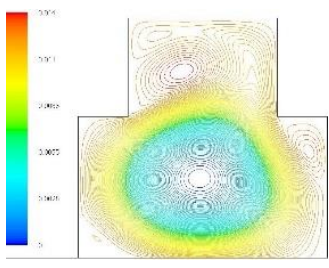

$\mathrm{Ra}=10^{4}$

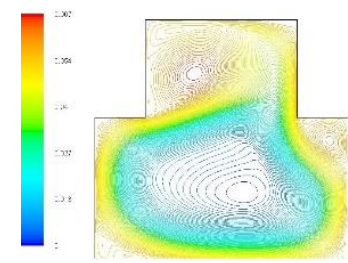

$\mathrm{Ra}=10^{6}$
Fig. 22 Contours of Streamlines for different Rayleigh number (for $\varphi=0.1$ and $\chi=0.6$ )

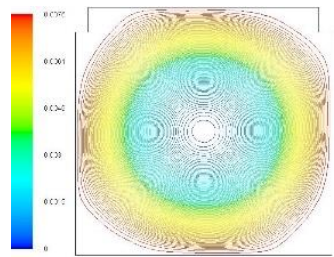

$\mathrm{Ra}=10^{3}$

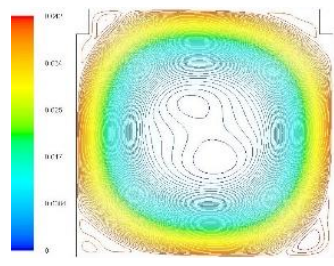

$\mathrm{Ra}=10^{5}$

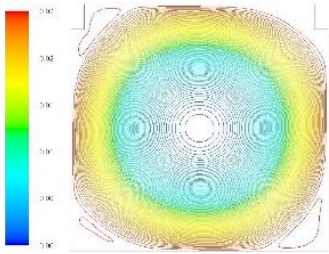

$\mathrm{Ra}=10^{4}$

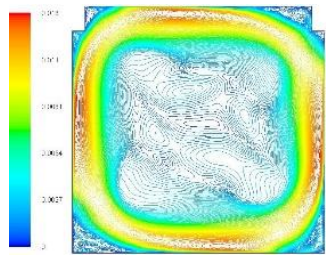

$\mathrm{Ra}=10^{6}$
Fig. 23 Contours of Streamlines for different Rayleigh number (for $\varphi=0.1$ and $\chi=0.9$ )

\subsection{Effect of $\chi$ of Enclosure on Heat Transfer}

Contours of static temperature and streamlines are shown in Fig. 18-23 for different $\mathrm{x} / \mathrm{L}$ ratios of the cavity $(\chi)$. With the increasing value of $\chi$, there is a significant difference in the contours. It has been seen by analyzing the contours that temperature distribution is prominently maximum when $\chi$ approximates unity. Variations of the average heat transfer coefficient and average Nusselt number are shown in Fig. 24. It is seen that both the average heat transfer coefficient and average Nusselt number decrease up to $\chi=0.6$ along with the increasing value of the Rayleigh number. Both the parameter value further increase with the increase of the Rayleigh number.

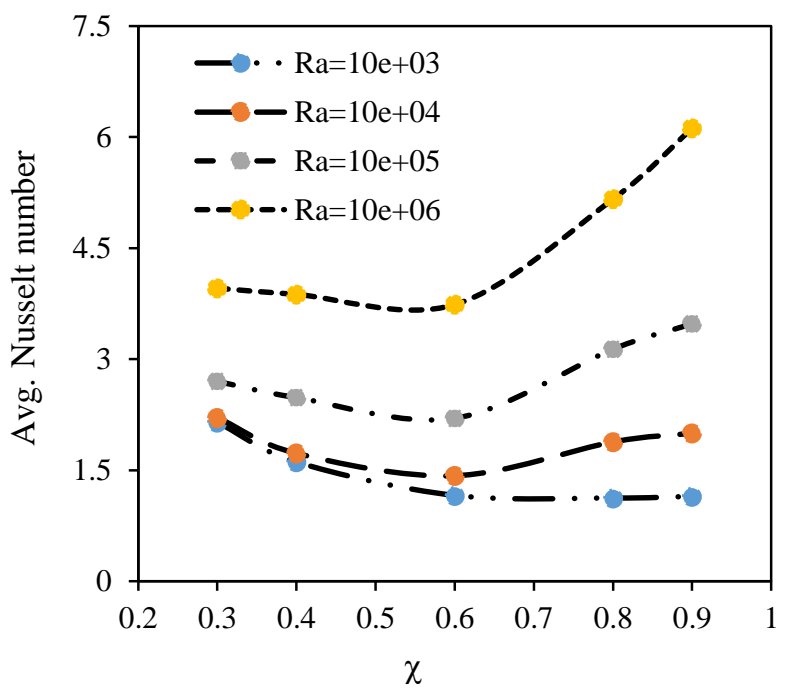

(a)

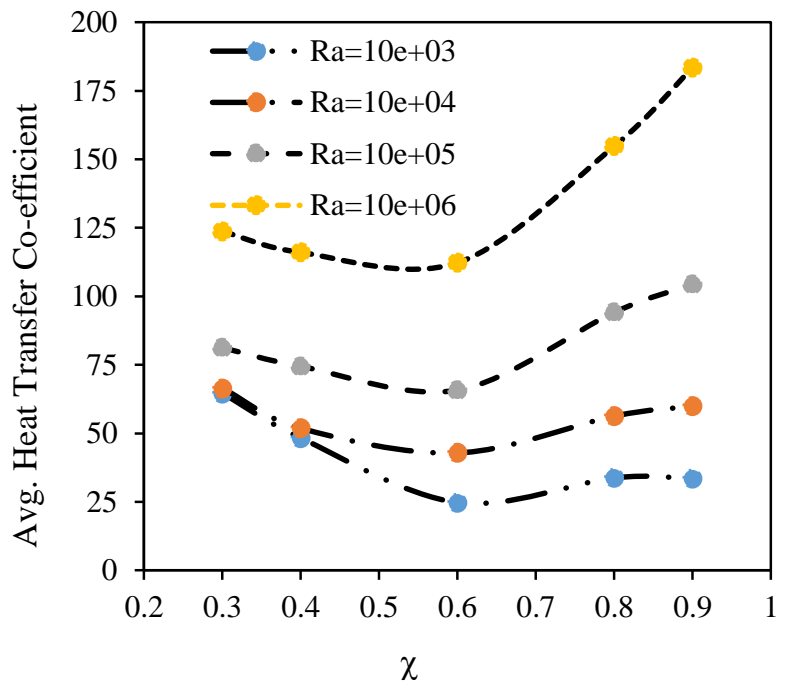

(b)

Fig. 24 Variation of average (a) Nusselt number and (b) convective heat transfer coefficient with different $\mathrm{x} / \mathrm{L}$ ratios for different Rayleigh numbers $(\varphi=0.07)$

\section{Conclusion}

A comprehensive and detailed analysis of natural convection in an inverted T-shaped enclosed cavity filled with nanofluid has been performed. The assessment has been executed to study the enormous increase in heat transfer using 
nanofluid instead of pure heat transfer fluids. The parameters that have been investigated in this analysis are -nanoparticle volume fraction, Rayleigh number, and $\mathrm{x} / \mathrm{L}$ ratio. Results found in this analysis indicate that-

- A remarkable increase in average heat transfer occurs with the gradual increase in the volume fraction of nanoparticles in the nanofluid. On the other side, the average Nusselt number decreases instead. A maximum $10 \%$ nanoparticle volume fraction has been used in this experiment. This analysis could be done using nanoparticle volume fraction beyond $10 \%$. The reduction of the average Nusselt number is slight for lower Ryleigh numbers $\left(\mathrm{Ra}=10^{3}\right.$ and $\left.10^{4}\right)$, whereas the reduction is prominent in higher Rayleigh numbers $\left(\mathrm{Ra}=10^{5}\right.$ and $\left.10^{6}\right)$

- Both the Nusselt number and average heat transfer coefficient decrease with an increase in $\mathrm{x} / \mathrm{L}=$ up to 0.6 . After that value of $\mathrm{x} / \mathrm{L}$, both of the parameters start increasing. This occurrence can be seen for $\mathrm{Ra} \geq 10^{4}$. In the case of $\mathrm{Ra}=10^{3}$, both the parameter's values reduce with the $\mathrm{x} / \mathrm{L}$.

- The value of average heat transfer coefficient as well as avg. Nusselt number rises with the increase of the Rayleigh number.

\section{References}

[1] Choi, S.U. and Eastman, J.A., 1995. Enhancing thermal conductivity of fluids with nanoparticles (No. ANL/MSD/CP-84938; CONF-951135-29). Argonne National Lab., IL (United States).

[2] Maxwell, J.C., 1873. A treatise on electricity and magnetism (Vol. 1). Clarendon press.

[3] Eastman, J.A., Choi, S.U.S., Li, S., Yu, W. and Thompson, L.J., 2001. Anomalously increased effective thermal conductivities of ethylene glycol-based nanofluids containing copper nanoparticles. Applied Physics Letters, 78(6), pp.718-720.

[4] Xie, H., Lee, H., Youn, W. and Choi, M., 2003. Nanofluids containing multiwalled carbon nanotubes and their enhanced thermal conductivities. Journal of Applied Physics, 94(8), pp.4967-4971.

[5] Jana, S., Salehi-Khojin, A. and Zhong, W.H., 2007. Enhancement of fluid thermal conductivity by the addition of single and hybrid nano-additives. Thermochimica Acta, 462(1-2), pp.45-55.

[6] Xuan, Y. and Li, Q., 2000. Heat transfer enhancement of nanofluids. International Journal of Heat and Fluid Flow, 21(1), pp.58-64.

[7] Eastman, J.A., Choi, U.S., Li, S., Thompson, L.J. and Lee, S., 1996. Enhanced thermal conductivity through the development of nanofluids. MRS Online Proceedings Library (OPL), 457.

[8] Nnanna, A.A., 2007. Experimental model of temperaturedriven nanofluid, Journal of Heat Transfer, 129(6), pp. 697-704.

[9] Ali, M., Zeitoun, O., Almotairi, S. and Al-Ansary, H., 2013. The effect of alumina-water nanofluid on natural convection heat transfer inside vertical circular enclosures heated from above. Heat Transfer Engineering, 34(15), pp.1289-1299.
[10] Ho, C.J., Liu, W.K., Chang, Y.S. and Lin, C.C., 2010. Natural convection heat transfer of alumina-water nanofluid in vertical square enclosures: An experimental study. International Journal of Thermal Sciences, 49(8), pp.1345-1353.

[11] Saleh, H., Roslan, R. and Hashim, I., 2011. Natural convection heat transfer in a nanofluid-filled trapezoidal enclosure. International Journal of Heat and Mass Transfer, 54(1-3), pp.194-201.

[12] Brinkman, H.C., 1952. The viscosity of concentrated suspensions and solutions. The Journal of Chemical Physics, 20(4), pp.571-571.

[13] Maxwell-Garnett, J.C., 1904. Colours in metal glasses and in metallic films. Phil. Trans. R. Soc. Lond, A, 203, pp.385-420.

[14] Ghasemi, B. and Aminossadati, S.M., 2009. Natural convection heat transfer in an inclined enclosure filled with a water- $\mathrm{CuO}$ nanofluid. Numerical Heat Transfer, Part A: Applications, 55(8), pp.807-823.

[15] Abouali, O. and Ahmadi, G., 2012. Computer simulations of natural convection of single phase nanofluids in simple enclosures: a critical review. Applied Thermal Engineering, 36, pp.1-13.

\section{NOMENCLATURE}

\begin{tabular}{|c|c|c|}
\hline Symbol & Full meaning & Unit of symbol \\
\hline$S$ & $\begin{array}{c}\text { Height and Width of } \\
\text { Cavity }\end{array}$ & $\mathrm{m}$ \\
\hline$\phi$ & $\begin{array}{c}\text { Fraction of } \\
\text { nanoparticle volume }\end{array}$ & \\
\hline$T$ & Temperature & $\mathrm{K}$ \\
\hline$P$ & Pressure & $\mathrm{Pa}$ \\
\hline$t$ & Time & second \\
\hline$x, y$ & $\begin{array}{c}\text { Dimensional Space } \\
\text { Coordinate }\end{array}$ & $\mathrm{m}$ \\
\hline$g$ & $\begin{array}{l}\text { Gravitational } \\
\text { acceleration }\end{array}$ & $\mathrm{ms}^{-2}$ \\
\hline$R a$ & Rayleigh number & \\
\hline$h$ & $\begin{array}{c}\text { Heat transfer } \\
\text { coefficient }\end{array}$ & $W-m^{-2} K^{-1}$ \\
\hline$\alpha$ & Thermal diffusivity & $m^{2} s^{-1}$ \\
\hline$\beta$ & $\begin{array}{c}\text { Thermal expansion } \\
\text { coefficient }\end{array}$ & $\mathrm{K}^{-1}$ \\
\hline$\mu$ & Dynamic viscosity & $\mathrm{Nsm}^{-2}$ \\
\hline$v$ & Kinematic viscosity & $m^{2} s^{-1}$ \\
\hline$\rho$ & Density & $\mathrm{kg} / \mathrm{m}^{3}$ \\
\hline$k$ & $\begin{array}{c}\text { Thermal } \\
\text { conductivity }\end{array}$ & $\mathrm{W}-\mathrm{m}^{-1} \mathrm{~K}^{-1}$ \\
\hline$C p$ & Specific heat & $\mathrm{J}-\mathrm{kg}^{-1} \mathrm{~K}^{-1}$ \\
\hline $\mathrm{Nu}$ & Nusselt number & \\
\hline$n f$ & Nanofluid & \\
\hline$\chi$ & $\begin{array}{l}x / L \text { Ratio of the } \\
\text { enclosure }\end{array}$ & \\
\hline
\end{tabular}

